\title{
A REALIDADE PARA ALÉM DO ESPELHO DE NARCISO
}

\author{
Érico Bruno Viana Campos \\ Universidade Estadual Paulista "Julio de Mesquita Filho" - UNESP
}

\section{Publicação}

Perez, D. O., Bocca, F. V., \& Bocchi, J. C. (2014). Ontologia sem Espelhos: Ensaio sobre a realidade: Descartes - Locke - Berkeley - Kant - Freud. Curitiba: CRV.

\section{RESENHA}

A questão sobre o estatuto da realidade é fundamental para a Filosofia. A interrogação sobre o que é real ou não, bem como o seu sentido último, é uma das perguntas básicas que instaura a investigação filosófica. Na tradição ocidental e moderna, se estabeleceram duas grandes respostas a esse problema ontológico: na relação entre a realidade externa e a consciência humana, ou a realidade externa é o fundamento do ser, em uma postura empirista e naturalista, ou o é a consciência humana, em uma postura idealista e racionalista. De todo modo, as duas posturas refletem um mesmo eixo geral de articulação do problema, calcado em uma lógica da representação como mediador entre o pólo da realidade subjetiva e o pólo da realidade objetiva, como duas faces de uma mesma moeda. Esse espelhamento na configuração e compreensão do estatuto do sujeito e do objeto marcou a tradição filosófica do qual somos herdeiros, estando presente até hoje em nosso senso comum. Contudo, a filosofia contemporânea se instaurou a partir de uma crítica da visão ontológica refém desse espelhamento narcísico, propondo alternativas à lógica da representação e também a uma concepção de que a natureza das coisas, tanto a realidade objetiva quanto a realidade subjetiva, sejam dadas por si sós e auto-fundadas, indicando que antes são constituídas e atravessadas por arranjos de sentido que as configuram.

É nesse quadro de referência geral que se insere o livro ora resenhado, uma publicação conjunta de docentes vinculados a grupos de pesquisa em filosofia da psicanálise, que propõem um ensaio de crítica sobre a temática a partir de três diferentes perspectivas: o da ficção-literatura, o da tradição filosófica moderna e o da psicanálise. O objetivo é reposicionar os fundamentos da questão, mostrando como diferentes tradições contribuem para sua configuração, de forma que ao reformular os parâmetros da pergunta se transforme o próprio horizonte da ontologia. A hipótese implícita é que as contribuições da psicanálise freudiana possam ser originais na ruptura com os termos da questão, indicando a fragilidade dessas construções e propondo arranjos conceituais que extrapolam esse esquema clássico. Para tanto, é 
apresentado um ensaio estruturado em quatro partes. A primeira parte, intitulada, "A linguagem da realidade", desenvolve o eixo da ficção-literatura. A segunda parte, intitulada "O sujeito da realidade", desenvolve o eixo da tradição filosófica moderna. A terceira e quarta partes, intituladas, respectivamente, "O teste da realidade" e "Construção intrassubjetiva do eu", desenvolvem o eixo da psicanálise.

O livro parte de um proêmio introdutório, onde a questão ontológica sobre a realidade é relançada, interrogando os seus próprios fundamentos. Em outras palavras, trata-se de questionar as condições de possibilidade da realidade, em suas categorias de materialidade, espacialidade, temporalidade, causalidade, etc. Nessa apreciação, os autores consideram então que a pergunta sobre a realidade supõe tanto uma linguagem, entendida como conjunto de conceitos, regras e argumentações, quanto uma posição de sujeito, entendida como um lugar de onde se enuncia o interrogante, de tal forma que: "Linguagem articulada e conceitos e argumentos e Sujeito da enunciação se conformam num dispositivo teórico que possibilita a pergunta e eventual resposta" (p. 08). Entende-se ainda a questão parte do duplo recurso a uma ficção originária, definida como "postulado, axioma ou conceito, que ordena todos os outros num dispositivo" ( $p$. 08), e a uma pressuposição de interior/exterior compreendida como eixo de configuração das relações de oposição dentro do dispositivo teórico. Nesse sentido, trata-se de dar um passo atrás na consideração da realidade como um fato, tratando-a como fruto de um dispositivo teórico-conceitual e, portanto, como um constructo que é especulativo e ficcional.

O primeiro movimento desse ensaio passa por um resgate da natureza ficcional da realidade, dimensão que foi sobremaneira excluída pela tradição filosófica e científica moderna por meio da dicotomização entre razão e emoção e, doravante, entre arte e ciência. O percurso se dá pela literatura de Jorge Luis Borges, não obstante o mesmo autor que fomentou o questionamento epistemológico de Foucault (1966/1981) em sua proposta de uma arqueologia das ciências humanas. Se no caso de Foucault o estranhamento diante da taxonomia absurda proposta no texto sobre a "biblioteca chinesa" serviu de inspiração disparadora para questionar o impensado no vínculo entre as palavras e as coisas, neste o mote são as referências de Borges aos filósofos e à filosofia, apontando a natureza arbitrária e ficcional de toda metafísica. O percurso se dá principalmente pelos textos em que Borges comenta Nietzsche, Platão e Pascal para apontar a realidade metafórica de todo o discurso sobre o ser e, principalmente, a ideia de que essa operação metafórica se sustente em algo que é da ordem de um esquecimento. É o esquecimento acerca do solo de significações fundantes do ser que permite que a realidade possa ser destacada e tomada de forma independente e autônoma.

Esse primeiro ensaio serve então como um movimento de desvelamento e crítica por meio da literatura, que vem de encontro aos questionamentos 
ontológicos da filosofia contemporânea, em especial os autores que se colocam nos desdobramentos da tradição do estruturalismo linguístico e da filosofia analítica, em que se destacam, além do próprio Foucault, Richard Rorty. Este último autor não deixa de reconhecer uma realidade externa, mas questiona a existência de características essenciais que poderiam chegar a definir um mundo independentemente de sua descrição, de tal forma que a existência se dá em ou a partir de um vocabulário. Assim, racionalidade e objetividade nada mais seriam do que formas de consenso e coerência semântica. Além disso, é de Rorty (1979/1995), em sua crítica do fundacionismo metafísico a partir do neopragmatismo, a proposição da metáfora da ausência de espelhos na apreciação da realidade, que é assumida pelos autores do livro em seu título. Contudo, o caminho que leva a essa desconstrução passa antes pela tradição da metafísica moderna.

O segundo ensaio trata do eixo geral de compreensão do sujeito moderno fundado em um sujeito transcendental do conhecimento como atributo da consciência reflexiva e volitiva humana, por meio do percurso que vai de Descartes, passando pelas tendências racionalistas e empiristas, até a síntese kantiana. Esse percurso filosófico, bem estabelecido e conhecido, é apresentado em suas linhas gerais por meio de breves incursões em textos dos filósofos elencados no subtítulo do livro. O ponto de chegada é a crítica kantiana da posição solipsista acerca do sujeito, que marcou a tradição moderna em suas vertentes epistemológicas. Como se sabe o cerne da crítica de Kant está em mostrar a indissociabilidade da experiência interna e externa, por meio da proposição de da noção de uma consciência para si e das categorias apriorísticas do conhecimento. Os autores fazem esse percurso para cair na discussão sobre o teste da realidade e sobre a natureza do sonho, da ilusão, do delírio e da própria loucura. Nesse sentido, em uma perspectiva kantiana, seria possível à razão transcendental fazer a distinção efetiva entre realidade e ilusão: "Se o evento concorda com a experiência (esquematismo dos conceitos e princípios do entendimento) então o evento é real" (p. 46).

É no esteio dessa tradição moderna que se insere o trabalho de Freud, em parte se apropriando e partindo desses quadros de referência conceitual, mas também propondo rupturas em relação a esses esquemas. Os autores propõem investigar duas dimensões onde essa tensão pode ser evidenciada e os indícios de ruptura notados, a saber, o teste de realidade e a constituição do eu. A hipótese é que Freud fornece uma concepção alternativa de eu que se distancia do solipsismo e racionalismo modernos: "É nesta dobradiça, entre a filosofia moderna e o advento da psicanálise, que aparece a possibilidade de formulação do problema ontológico em questão" (p. 49).

O capítulo sobre o teste da realidade apresenta de forma bastante minuciosa a construção e as transformações desse conceito e de sua problemática, desde os textos pré-psicanalíticos até o final da obra freudiana, 
com destaque para sua tematização a partir dos dois princípios do funcionamento mental e do narcisismo. Todo o problema acerca do teste da realidade em Freud está em que em sua apreciação mais superficial ele acaba por pressupor aquilo que deve explicar, ou seja, que haja efetivamente parâmetros perceptivos e racionais para a distinção da realidade. Em geral, em psicanálise a possibilidade de fazer o teste da realidade é tomada como uma etapa do desenvolvimento do aparelho psíquico que costuma ser alcançada nas estruturas neuróticas, mas que é também um parâmetro para avaliação da própria categorização psicopatológica, de forma que se acaba incorrendo em circularidade e petição de princípio.

Um olhar mais detido sobre a construção conceitual do conceito, contudo, mostra que, embora não chegue a constituir uma teoria sistemática, há um conjunto complexo e articulado de elementos envolvidos do ponto de vista da dinâmica do aparelho psíquico: a inibição do impulso em processo primário, a modulação da atenção perceptiva, a mobilização dos processos secundários de pensamento, a efetivação de um juízo de reconhecimento do objeto e, por fim, o controle da ação motora (Porchat, 2005). Esse esquema, por sua vez, é tributário de uma visão psicológica e psiquiátrica das funções mentais, de cunho mecanicista e associacionista, mas que prescinde de uma posição realista. Muitos comentadores (Loffredo, 2004; Campos, 2014), insistem em marcar a posição freudiana quanto ao estatuto da representação como da ordem de um associacionismo nominalista. Nessa perspectiva, a representação mental dos objetos da realidade é construída associativamente a partir da experiência e se refere aos objetos, nomeando-os. Mas essa referência nominal não tem o estatuto de uma criação do eu que passa a legitimar a realidade, muito menos a de uma legitimação empírica da realidade para a construção representacional mental. Desse modo, trata-se de uma posição que ultrapassa o realismo e o idealismo clássicos. Contudo, uma análise epistemológica desses pressupostos e também uma sistematização da contribuição freudiana para essa temática é algo que não se efetivou. Apesar disso, os autores conseguem trabalhar os meandros dessa tensão, mostrando então como a posição freudiana pode apontar que a "constituição da subjetividade se dá no entrecruzamento entre a demanda do interior e seu atendimento a partir do exterior" (p. 86), indicando não só a oposição, mas também uma relação hesitante que indicaria uma interrelação entre mundo externo e mundo interno, ultrapassando uma visão dicotômica sobre sujeito e objeto, como uma visão apressada sobre o teste da realidade pode sugerir.

A desconstrução dessa noção passa por um exame mais minucioso sobre o estatuto do Eu e também sobre sua constituição, o que leva necessariamente ao tema do narcisismo. Uma contribuição fundamental do pensamento freudiano às concepções filosóficas de sujeito está justamente em poder pensar a gênese do eu e de seus atributos racionais, não tomando o eu como dado e auto-fundado. 
O conceito de narcisismo é fundamental para pensar a constituição do eu, já que é a partir da identificação narcísica com o objeto que essa instância psíquica se estrutura. Essa é a noção de uma construção intrassubjetiva do eu, que é a tônica do pensamento freudiano mas também costuma ser alvo de discussões. Isto se dá porque muitas vezes a noção de narcisismo primário, a partir de indicações freudianas e na sequência das teorias pós-freudianas, foi entendido como um estado anobjetal primário, o que, do ponto de vista filosófico, endossaria uma posição solipsista de sujeito, em que as pulsões teriam primazia sobre os objetos da realidade e, portanto, em que o eu continuaria operando como causa do mundo. Essa posição, que prioriza a dimensão pulsional na afirmação do sujeito psicanalítico em detrimento dos objetos, contudo, é contrabalanceada por uma posição que toma os objetos como elementos constitutivos do circuito pulsional, por meio da concepção dos processos de identificação como modeladores do circuito pulsional, o que estabelece uma concepção mais alteritária e intersubjetiva sobre o sujeito psicanalítico (Coelho Junior, 2002). Essas duas vertentes convergem justamente na problemática do narcisismo.

Em sua análise, os autores fazem um percurso minucioso sobre essa questão, desconstruindo alguns pontos desse debate. Em primeiro lugar, caracterizam detalhadamente os níveis de compreensão da noção de objeto da pulsão, para mostrar que a noção de objeto da pulsão não se confunde com objeto do eu ou da realidade. Passam em revista as concepções de objetos originários da pulsão e sua relação com a formação do eu e da realidade, para afirmar uma noção mais nuançada em que o eu aparece como uma construção fronteiriça de articulação entre dois mundos co-constituídos, a realidade interna e a realidade externa. Nesse percurso se toma novamente o fio da meada dos processos do aparelho psíquico em direção a realidade, com destaque para as funções de inibição, de atenção e de julgamento, para afirmar que na perspectiva freudiana o eu é antes uma construção advinda da própria experiência e que em seus diferentes níveis de organização modula a própria experiência subjetiva. Além disso, em sua estrutura intrapsíquica, o aparelho psíquico opera segundo princípios e estruturas próprias do fantasiar, indicando então a natureza ficcional da realidade psíquica.

Ao final dos dois ensaios sobre a psicanálise, os autores chegam a um mapeamento bastante preciso do percurso freudiano sobre a questão, levandoos então a uma breve conclusão, em que a concepção freudiana sobre os processos de identificação é indicada como uma contribuição original e alternativa ao dispositivo moderno para a constituição do problema da realidade, calcado em uma noção mais construtivista sobre o eu, ultrapassando uma perspectiva solipsista e se aproximando de uma perspectiva ficcional. Embora reconheçam as ambiguidades e limitações do quadro de referência freudiano, apontam esse ponto de viragem, indicando um ultrapassamento do dispositivo 
teórico da modernidade, deixando para trás "toda forma substancial e autônoma de fundação da realidade e da subjetividade" (p. 113). Dessa forma, a hipótese inicialmente implícita é explicitada e justificada, indicando então que a contribuição freudiana de fato tem destaque e prevalência sobre as demais. Nesse sentido, Freud é o ponto de chegada na desconstrução do dispositivo narcísico de espelhamento entre eu e natureza.

O livro realiza então seus objetivos, dentro de sua proposta ensaística, fazendo um percurso interessante sobre essa problemática tão fundamental e pertinente, ainda mais tendo em vista as discussões contemporâneas no campo da filosofia e das ciências humanas, além da própria psicanálise. De fato, cada vez mais a psicanálise segue o caminho de aprofundamento dessa ruptura instaurada por Freud, mesmo que para isso precise recorrer a quadros epistemológicos que transcendam os seus de origem. A questão é que Freud parte de uma visão cientificista naturalista e dos desdobramentos epistemológicos da filosofia kantiana como fundamento epistemológico tácito de sua teorização. Contudo, o saber e o método psicanalítico vão instaurando rupturas com esses próprios dispositivos teórico-conceituais, mas essa ultrapassagem é implícita, ou, pelo menos, não é tematizada ou eleita pelo próprio movimento psicanalítico como um elemento prioritário de contribuição da psicanálise para a história das ideias. O maior indicativo disso é que não se pode afirmar uma teoria do sujeito em Freud. Essa análise coube muito mais ao campo da filosofia da psicanálise, que vem paulatinamente trabalhando essas questões, principalmente a partir do aporte das teorias pós-freudianas, em especial na vertente lacaniana, e das diferentes vertentes da filosófica contemporânea, como apontado no início desta resenha. Diante disso, o que faz falta no livro é justamente uma contextualização e caracterização mais ampla desse debate. Contudo, não era a intenção original do ensaio ir além da indicação dessa viragem, ficando a tarefa à cargo do leitor e de outras contribuições. Nesse sentido, o grande mérito do livro é instigar um convite à filosofia da psicanálise por meio de um percurso intrínseco à obra freudiana no esteio da tradição filosófica.

Porém, ao final desse percurso, o leitor fica com uma impressão curiosa a respeito do título do livro. É que, a princípio, o subtítulo dá a entender que Descartes, Locke, Berkeley, Kant e Freud estão em pé de igualdade em sua contribuição para o ensaio, o que não é verdade. A psicanálise é um ponto de inflexão nessa tradição filosófica representada pelos outros autores e o próprio livro se debruça muito mais sobre Freud do que sobre os demais. Além disso, falta indicar no subtítulo a contribuição da perspectiva ficcional e literária, representada na primeira parte por Borges. Na verdade, mais do que um preâmbulo satírico de crítica e desconstrução, os dispositivos estéticos e conceituais da arte também são uma importante via de construção de realidades, que incide também sobre a história das ideias e campos de saber. Afinal, há toda 
uma vertente contemporânea, não só em psicanálise, que privilegia uma fundamentação estética para o saber. Nesse sentido, a psicanálise se aproximaria muito mais de uma estilística da existência do que de um saber da ordem do conhecimento. Por conta disso, um desdobramento interessante do que é delineado nesse livro seria o aprofundamento dessa outra vertente de ruptura com o espelhamento ontológico da realidade. Em todo caso, chama a atenção também essa omissão no título. Esse duplo lapso nos parece indicativo ainda de certa deferência à tradição filosófica moderna, em que psicanálise e literatura são marginais em relação ao rol dos grandes pensadores. Chistes à parte, sua caracterização só vem confirmar a importância desse movimento de ruptura com a tradição, no qual o ensaio vem se situar justamente no ponto de passagem.

\section{REFERÊNCIAS}

Campos, E. B. V. (2014). Limites da representação na metapsicologia freudiana. São Paulo: EDUSP.

Coelho Junior, N. E. (2002). Variações do lugar do objeto na psicanálise freudiana. In L. M. Simão, M. T. C. C. De Souza, \& N. E. Coelhor Junior (Eds.), Noção de objeto, concepção de sujeito: Freud, Piaget e Boesch (p. 11-52). São Paulo, SP: Casa do Psicólogo.

Loffredo, A. M. (2004). A noção de representação na metapsicologia freudiana. In F. Herrmann, \& T. Lowenkron, (Eds.), Pesquisando com o método psicanalítico (p. 309-322). São Paulo, SP: Casa do Psicólogo.

Foucault, M. (1981). As palavras e as coisas: Uma arqueologia das ciências humanas. São Paulo, SP: Martins Fontes. (Originalmente publicado em 1966)

Porchat, P. (2005). Freud e o teste da realidade. São Paulo, SP: Casa do Psicólogo.

Rorty, R. (1995). A filosofia e o espelho da natureza. Rio de Janeiro, RJ: RelumeDumará. (Originalmente publicado em 1979).

Sobre o autor

Érico Bruno Viana Campos é psicólogo, mestre e doutor em psicologia pelo IPUSP. Professor Assistente Doutor do Departamento de Psicologia da UNESP

Bauru. ebcampos@fc.unesp.br

Recebido em: 28/09/2016

Revisado em: 14/12/2016

Aceito em: 13/02/2017 